\title{
BRAF mutations, microsatellite instability status and cyclin DI expression predict metastatic colorectal patients' outcome
}

\author{
Z Saridaki $^{1,2,4}$, D Papadatos-Pastos ${ }^{2,4}$, M Tzardi $^{3}$, D Mavroudis ${ }^{1,2}$, E Bairaktari ${ }^{1,3}$, H Arvanity ${ }^{1,3}$, E Stathopoulos ${ }^{3}$, \\ V Georgoulias ${ }^{1,2}$ and J Souglakos ${ }^{*, 1,2}$
}

'Laboratory of Tumor Cell Biology, School of Medicine, University of Crete, Crete, Greece; ²Department of Medical Oncology, University General Hospital, Heraklion, Crete, Greece; ' 2 aboratory of Pathology, University General Hospital, Heraklion, Crete, Greece

BACKGROUND: The significance of BRAF mutations, microsatelite instability (MSI) status and cyclin DI expression in patients with metastatic colorectal cancer ( $\mathrm{mCRC}$ ) was evaluated.

METHODS: Primary tumours from I 44 patients treated for mCRC were assessed for BRAF (V600E) mutation, MSI status and cyclin DI. The data were correlated with progression-free survival (PFS) and overall survival (OS).

RESULTS: BRAF mutations were detected in 10 (out of 22, 45\%) patients with MSI-H tumours compared with 2 (out of I22, I.6\%) in those with microsatellite stable tumours $(P<0.00 \mathrm{I})$. The presence of BRAF mutations was correlated with cyclin $D I$ overexpression (7 out of 26 patients, $58 \%$ vs 5 out of 118 patients, I4\%; $P=0.001$ ). Patients with BRAF-mutated primary tumours had a significantly decreased PFS (2.7 vs 9.8 months; $P<0.00$ I) and median OS ( 4 vs 30 months; $P<0.00$ I) than patients with wild-type (wt) tumours. Patients with MSI-H and BRAF-mutated tumours experienced significantly lower PFS (3.I vs II.4 months; $P=0.008)$ and OS (I4.5 vs 35.5 months; $P=0.004)$ than patients with $M S I-H$ and BRAF wt tumours. Similarly, BRAF mutations and cyclin DI overexpression were correlated with decreased PFS (3.I vs 8.6 months; $P=0.03$ ) and $O S$ (I7.8 vs 39.2 months; $P=0.0 I$ ).

CONCLUSION: BRAF V600E mutations are associated with MSI-H status and cyclin DI overexpression and characterize a subgroup of patients with poor prognosis.

British Journal of Cancer (2010) I 02, 1762-1768. doi:I0.1038/sj.bjc.6605694 www.bjcancer.com

Published online 18 May 2010

(c) 2010 Cancer Research UK

Keywords: BRAF mutations; MSI status; cyclin DI expression; metastatic CRC

Colorectal cancer (CRC) remains a major public health problem in the Western world with an estimated 146970 new cases and 49920 deaths in the United States in 2009 (Jemal et al, 2009). Some molecular markers have already been incorporated in the treatment of CRC patients. Indeed, the knowledge of KRAS mutational status of a primary tumour is now mandatory for the treatment of metastatic disease, as it is a predictor of resistance to monoclonal antibodies of the epidermal growth factor receptor (anti-EGFR moAbs) (Bokemeyer et al, 2008; Douillard et al, 2009; Hecht et al, 2009; Tol et al, 2009; Van Cutsem et al, 2009). In addition, BRAF V600E mutation identifies a subgroup $(<10 \%)$ of patients with unfavourable prognosis (Di Nicolantonio et al, 2008; Souglakos et al, 2009); conversely, the presence of a defective tumoural DNA mismatch repair (dMMR) system seems to be a favourable prognostic factor (French et al, 2008), although these patients seem to respond worse to standard adjuvant chemotherapy (Hemminki et al, 2000; Samowitz et al, 2001; Popat et al, 2005; French et al, 2008).

The RAS-RAF-MEK-ERK-MAP kinase pathway mediates cellular responses to growth signals constituting an essential component of intracellular signalling from activated cell-surface

*Correspondence: Dr J Souglakos; E-mail: georgsec@med.uoc.gr

${ }^{4}$ These authors contributed equally to this work.

Received 27 January 20 I0; revised 8 April 20I0; accepted I 5 April 20 I0; published online 18 May 2010 receptors to transcription factors in the nucleus (Peyssonnaux and Eychene, 2001). In the BRAF gene, one of the three RAF genes and part of the above-mentioned pathway, the single substitution missense mutation V600E, located within the kinase domain, account for more than $80 \%$ of the described mutations. The $B R A F$ V600E mutation has been detected in a wide range of human cancers, including melanomas, thyroid carcinomas, sporadic CRC $(10 \%)$ and others. The V600E mutation results in a constitutive activation of the BRAF kinase promoting cell transformation (Davies et al, 2002; Preto et al, 2008).

In a retrospective study of sporadic metastatic colorectal cancer (mCRC), BRAF mutations, detected in $8 \%$ of patients, were emerged as an independent prognostic factor for both progressionfree survival (PFS) and overall survival (OS) (Souglakos et al, 2009). Similar findings were reported by Di Nicolantonio et al (2008) who concluded that the BRAF V600E mutation is not only inversely associated with response to anti-EGFR moAb therapy, but it is also associated with a worse prognosis.

The microsatellite instability (MSI), which is characterised by the absence of protein expression encoded by the corresponding MMR genes ( $h M L H 1, h M S H 2, h M S H 6$ or PMS2; Thibodeau et al, 1993, 1998; Popat et al, 2005), is observed in nearly all patients with CRC due to hereditary non-polyposis colon cancer (HNPCC) (Aaltonen et al, 1993, 1994; Thibodeau et al, 1993) and in 15-20\% of patients with sporadic CRC (Aaltonen et al, 1993). In its familial form, the genetic basis of instability is mainly (80\%) inherited 
germ-line mutations of the MMR genes (especially $h M L H 1$ and hMSH2; Leach et al, 1993; Peltomaki, 1994), whereas in the sporadic form, it is due to $h M L H 1$ inactivation by epigenetic hypermethylation of the promoter and less frequently to genetic alterations of $h M S H 2$ and $h M S H 6$ genes (Kane et al, 1997; Cunningham et al, 1998, 2001; Thibodeau et al, 1998). Microsatellite genotyping of CRC patients for clinically applicable diagnosis is based on specific standard criteria using specific panels (Boland et al, 1998). Since then, these panels have been clinically applicable for the diagnosis of CRC patients (Gryfe et al, 2000; Watanabe et al, 2001).

In CRC tumours, BRAF mutations seem to occur more frequently in cases characterised by dMMR (Rajagopalan et al, 2002). Moreover, several studies suggest that the BRAF V600E mutation occurs much more frequently in MSI-H tumours in comparison with microsatellite stable (MSS) tumours (50 vs $<5 \%$ respectively) (Wang et al, 2003; Domingo et al, 2004).

Cyclin D1 is a cell-cycle regulatory protein and its upregulation has been associated with increased proliferation and poor clinical outcome in various tumours (Le Marchand et al, 2003). Cyclin D1 is a key element in the downstream EGFR signalling pathway; KRAS mutations lead to the activation of the RAS-RAF-MEKERK-MAP kinase pathway by inducing cyclin D1 synthesis (Kobayashi et al, 2006). BRAF controls proliferation of human melanoma cells through the regulation of cyclin D1 and cyclindependent kinase inhibitor p2 $7^{\mathrm{Kip} 1}$ protein (Bhatt et al, 2005, 2007). Similarly, it has been reported that in CRC cells the decreased expression levels of pERK protein and cyclin D1 were more pronounced in cells carrying the $B R A F$ V600E mutation, and, that BRAF V600E-ERK signalling is also important in the regulation of proliferation by $\mathrm{p} 27^{\mathrm{Kip} 1}$ and cyclin D1 proteins in these cells (Preto et al, 2008).

The aim of this study was to investigate the clinical relevance of $B R A F$ V600E mutation status, cyclin D1 expression and MSI status of primary tumours of patients with $\mathrm{mCRC}$ treated with front-line 5FU-based chemotherapy.

\section{MATERIALS AND METHODS}

\section{Patient population and study design}

A total of 144 consecutive patients, with histologically confirmed $\mathrm{mCRC}$ and available tumour material for molecular analysis, who were treated at the University Hospital of Heraklion (Crete, Greece) between January 2002 and December 2006 were enrolled. The study was approved by the institutional ethics committee and all patients gave the informed consent for the use of the tissue material for translational research.

The majority of patients were treated in the context of two clinical trials conducted at our centre (Souglakos et al, 2006; Emmanouilides et al, 2007; Tables 1 and 2). Patients were evaluated at baseline and every four cycles of chemotherapy. Disease status was coded, without the knowledge of the laboratory analysis.

\section{Tissue selection and DNA extraction}

Formalin-fixed, paraffin-embedded tumour sections were reviewed by a pathologist (MT) to confirm the diagnosis and define tumourenriched areas for dissection. Ten serial sections of $5 \mu \mathrm{m}$ thickness were stained with nuclear fast red (Sigma-Aldrich, St Louis, MO, USA) and scrape dissection under a binocular microscope was performed for samples with $\geqslant 80 \%$ tumour cells; for samples with $<80 \%$ malignant cells, microdissection with the piezoelectric Eppendorf microdissector (Eppendorf, Hamburg, Germany) was performed. Isolated cancer cells were lysed in buffer containing Proteinase $\mathrm{K}$ at $60^{\circ} \mathrm{C}$ for $72 \mathrm{~h}$, followed by DNA extraction using the MasterPure Complete DNA and RNA Purification Kit according to the manufacturer's instructions (Epicentre Biotechnologies, Madison, WI, USA).

\section{BRAF testing}

The V600E BRAF mutation was detected by real-time PCR using the allelic discrimination method as previously described (Benlloch et al, 2006). In brief, the DNA extracted from tumoural cells was amplified with the use of a set of primers and two hydrolysis probes in the ABI PRISM 7900T Sequence Detection System (Applied Biosystems, Forest City, CA, USA). The two hydrolysis probes were labelled at 5 with VIC and FAM fluorophores reporters for the wild-type (wt) and the mutant allele respectively. The SDS 2.3 software (Applied Biosystems) was used for the analysis of the results.

\section{Immunohistochemistry for MMR and cyclin D1}

Tumour sections form each patient were selected for immunohistochemical staining using anti-hMLH1 and anti-hMSH2 (for the MMR definition as previously described; Lindor et al, 2002) and anti-cyclin D1 (Nosho et al, 2008) antibodies. In brief, immunostaining was performed using the UltraVision LP Large Volume Detection System AP Polymer (Thermo Scientific, Waltham, MA, USA). The primary antibodies and their corresponding dilutions used were: hMLH1 (Cell Marque, Rocklin, CA, USA; dilution $1: 50$ ), hMSH2 (Cell Marque Rocklin; dilution $1: 50$ ) and Cyclin D1 (Neomarker, Fermont, CA, USA; dilution 1:25). Nuclear immunostaining of lymphocytes and stromal cells served as internal positive control for hMLH1 and hMSH2. Tumours showing loss of nuclear hMSH2 or hMLH1expression were classified as hMLH1 or hMSH2 negative. In addition, for cyclin D1 a positive control slide from a case of mantle cell lymphoma was included and nuclear immunostaining was considered positive. Negative control slides were prepared by omitting the primary antibody. Nuclear cyclin D1 expression was recorded as no expression, weak expression or moderate/strong expression. Cyclin D1 overexpression was defined as $\geqslant 50 \%$ of tumour cells with weak nuclear staining or $\geqslant 20 \%$ of tumour cells with moderate/strong nuclear staining (Nosho et al, 2008).

\section{MSI testing and mismatch repair definition}

Microsatelite instability status was evaluated in all samples using the five microsatellite markers of the NCI reference panel (BAT-25 at $4 \mathrm{q} 12$, BAT-26 at 2p16, D2S123 at 2p16-p21, D5S346 at 5q21-q22 and D17S250 at $17 \mathrm{q} 11.2-\mathrm{q} 12$ ) and with two additional microsatellite markers of the alternative panel (D18S58 at 18q22-q23 and D18S61 at 18q22) (Boland et al, 1998). PCR for the abovementioned microsatellite markers was carried out on tumour and matched DNA from the adjacent normal colonic tissue. Standard PCR conditions were used and included $10 \times$ buffers, Taq gold and deoxynucleotide triphosphates adjusted to a final reaction volume of $25 \mu \mathrm{l}$ containing $100 \mathrm{ng}$ of genomic DNA (Boland et al, 1998; Watanabe et al, 2001).

Single-strand conformation polymorphism in non-denaturing environment (Makino et al, 1992) was performed after optimisation with a $7 \%$ polyacrylamide gel ( $5 \%$ glycerol) for the analysis of BAT-25 and BAT-26 PCR products. The PCR products of other microsatellite markers' were analysed in $7 \%$ polyacrylamide gels and silver-stained. Gels were scanned and the intensity of the bands corresponding to the microsatellite alleles was quantified by a digital image analysis system, as previously described (Saridaki et al, 2003). The analysis was repeated at least twice and the same results were obtained in all cases. MSI was diagnosed in case of an addition or deletion of one or more repeat units resulting in novel alleles. All the heterozygous cases, and those that were 
Table I Characteristics of enrolled patients and univariate analysis for PFS and OS

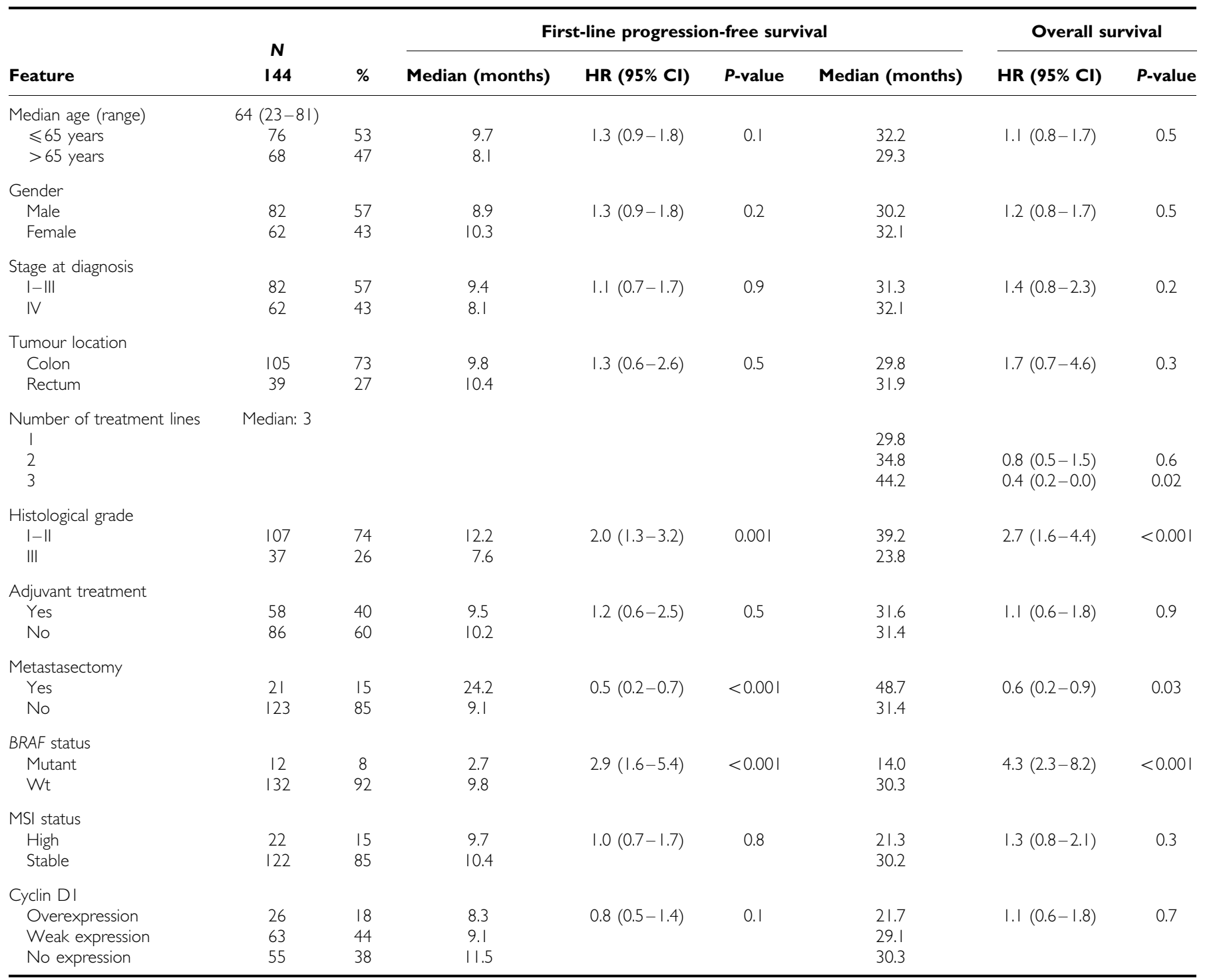

Abbreviation: $\mathrm{MSI}=$ microsatellite instability.

Table 2 BRAF mutation and MSI status and correlations with PFS and OS

\begin{tabular}{|c|c|c|c|c|c|}
\hline \multirow[b]{2}{*}{ Total $(n=144)$} & \multicolumn{2}{|c|}{ MSI-H, $n=22(15 \%)$} & \multicolumn{3}{|c|}{ MSS, $n=122(85 \%)$} \\
\hline & $N(\%)$ & Median (months) & $N(\%)$ & Median (months) & $P$-value \\
\hline \multicolumn{6}{|l|}{ Progression-free survival } \\
\hline BRAF mutant, $n=12(8 \%)$ & $10(45)$ & 3.1 & $2(1.6)$ & 1.6 & $0.003^{\&}$ \\
\hline BRAF $w t, n=132(92 \%)$ & $12(55)$ & 11.4 & $120(98.4)$ & 9.7 & $0.2^{@}$ \\
\hline$P$-value & & $0.008^{*}$ & & $<0.001^{\#}$ & \\
\hline \multicolumn{6}{|l|}{ Median overall survival } \\
\hline BRAF $w t, n=132(92 \%)$ & $12(55)$ & 35.5 & $120(98.4)$ & 30.2 & $0.4^{@}$ \\
\hline$P$-value & & $0.004 *$ & & $<0.001^{\#}$ & \\
\hline
\end{tabular}

Abbreviation: MSI = microsatellite instability. *P-value: MSI-H BRAF mutant vs MSI-H BRAF wt. ${ }^{\#} P$-value: MSS BRAF mutant vs MSS BRAF wt. ${ }^{\circledR} P$-value: MSI-H BRAF mutant vs MSS BRAF mutant. @P-value: MSI-H BRAF wt vs MSS BRAF wt.

constitutionally homozygous (non-informative) for a marker, were counted to estimate the MSI rate. If $\geqslant 30 \%$ of the loci examined showed MSI, the tumour was classified as MSI-H. If $<30 \%$ of the loci examined showed MSI, it was classified as MSI-L and if none of the examined loci showed instability, the tumour was classified as MSS (Boland et al, 1998). 


\section{Statistical analysis}

Associations between BRAF mutation status, dMMR, cyclin D1 expression and baseline characteristics were assessed using the Fisher's exact test for categorical variables or logistic regression for continuous variables. PFS was measured from the date of first-line therapy initiation to the first radiographic documentation of disease progression or death, and OS was calculated from the date of diagnosis of metastatic disease to death due to mCRC. Kaplan-Meier curves were used to describe the proportion of patients who remained free of events over the follow-up period. Associations between prognostic factors and PFS or OS were examined using Cox proportional hazards regression models. All reported $P$-values are two sided and not adjusted for multiple testing.

\section{RESULTS}

The median age of patients was 64 years and $57 \%$ of them were men. Metastasectomy was also performed in 21 (15\%) patients (Tables 1 and 2). The BRAF V600E mutation was detected in $12(8 \%)$ patients and $22(15 \%)$ tumours were characterised as MSI-H. MSI analysis using immunohistochemistry and molecular techniques presented $100 \%$ accordance (Figure $1 \mathrm{~A}$ and B). Cyclin D1 was overexpressed in $26(18 \%)$ patients, weakly expressed in $63(44 \%)$ and not expressed in 55 (38\%) (Figure 1C). There was no correlation between the presence of BRAF mutation, MSI-H and cyclin D1 expression, and the patient' gender, age, stage at diagnosis, histological grade and tumour location (all $P$-values $>0.05$ ).

The median time from initial diagnosis to diagnosis of metastatic disease was 19.3 months (95\% CI 14.6-20.3) for patients with early stage disease and the median interval from the diagnosis of metastatic disease to treatment initiation 0.8 months (95\% CI 0.5-1.1). All patients were treated with 5-FU-based first-line chemotherapy with or without moAb supplementation (Table 3 ). At the time of analysis 132 out of $144(92 \%)$ patients were dead, 128 (97\%) of them due to disease progression, $2(1.5 \%)$ due to toxicity and $2(1.5 \%)$ due to reasons unrelated with disease or treatment.

$B R A F$ mutations were present in 45 and $1.6 \%$ of the patients with MSI-H and MSS tumours respectively $(P<0.001)$. The detection of $B R A F$ mutations was also correlated with cyclin D1 expression as cyclin D1 overexpression was detected in 58 and $14 \%$ of $B R A F$ mutated and wt tumours respectively $(P=0.001$; Table 4$)$.

The median PFS of the whole group of patients was 9.5 months (95\% CI 8.4-10.8) and the corresponding median OS was 31.5 months (95\% CI 26.4-37.7). The median OS was 14 and 30 months for patients with $B R A F$-mutated and wt tumours respectively $(P<0.001$; Figure 2A). In addition, PFS was 2.7 and 9.8 months for patients with $B R A F$-mutated and wt primary tumours respectively $(P<0.001$; Figure 2B). Patients with MSI-H and BRAF-mutated tumours experienced significantly lower PFS (3.1 vs 11.4 months; $P=0.008)$ and OS (14.5 vs 35.5 months; $P=0.004)$ in comparison with those with MSI-H and BRAF wt tumours. Similarly, $B R A F$ mutations and cyclin D1 overexpression were correlated with decreased PFS (3.1 vs 8.6 months; $P=0.03)$ and OS (17.8 vs 39.2 months; $P=0.01$ ).

Univariate analysis (Tables 1 and 2) revealed significant associations of PFS with undifferentiated tumour histology $(P=0.001), B R A F$ mutations $(P<0.001)$ and inability of patients to undergo metastasectomy $(P<0.001)$. In addition, univariate analysis showed significant associations between OS and (1) tumour differentiation (grade 3) (PFS and OS: $P<0.001$ ); (2) BRAF mutations $(P<0.0001)$, (3) metastasectomy (OS: $P=0.03)$ and (4) the sum of treatment lines that a patient had the opportunity to receive $(P=0.02)$.

In multivariate analysis, $B R A F$ mutation and tumour grade were emerged as independent prognostic factors for reduced PFS
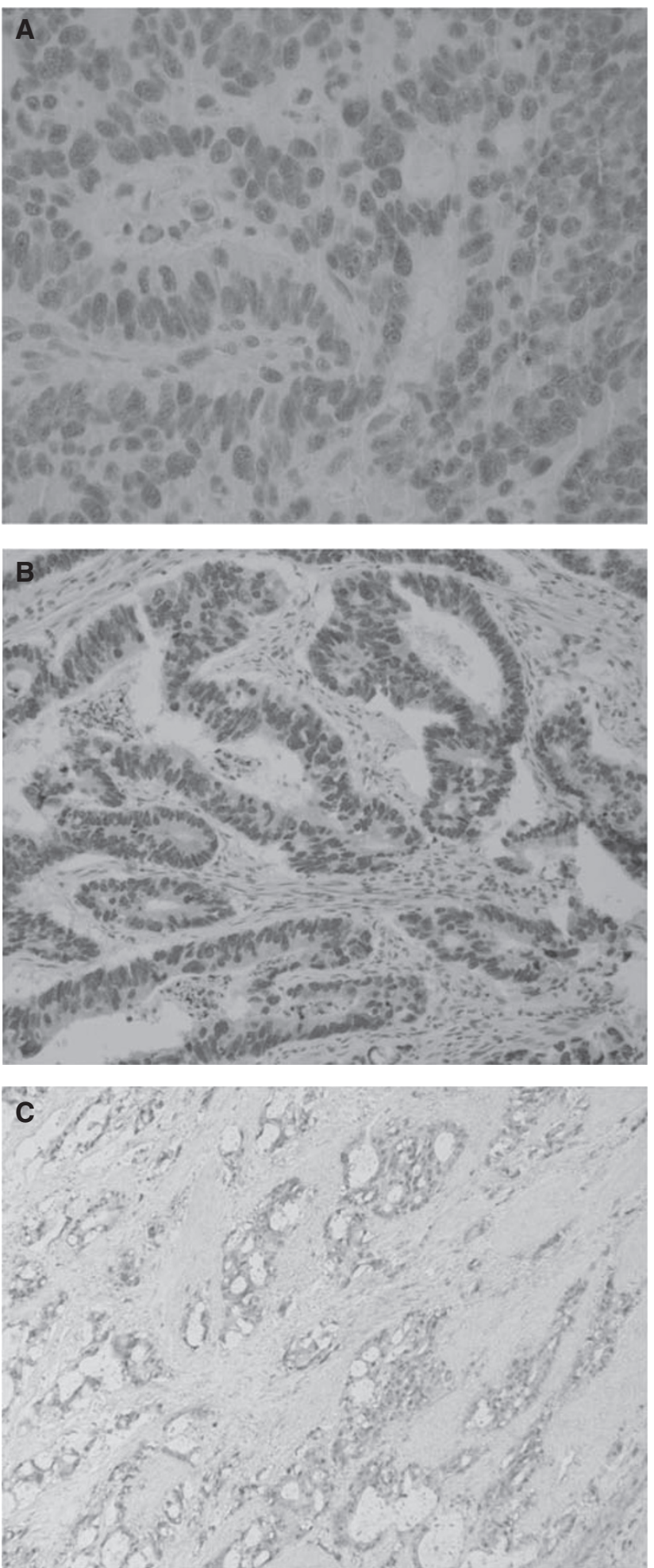

Figure I (A) $\mathrm{MLHI}(+)$ adenocarcinoma with moderate differentiation of the colon (original magnification, $\times 200)$. (B) MSH2(+) adenocarcinoma with moderate differentiation of the colon (original magnification, $\times$ 100). (C) Cyclin DI ( + ) adenocarcinoma moderate-poorly differentiated (original magnification, $\times 100$ ).

(HR 2.8, 95\% CI 1.4-5.7, $P=0.004$ and HR 2.0, 95\% CI $1.3-3.2$, $P=0.001$ respectively) and OS (HR 5.3, 95\% CI $2.5-11.3, P<0.001$ and HR $2.6,95 \%$ CI $1.6-4.4, P<0.001$ respectively). In addition, both metastasectomy and the number of administered treatment 
lines emerged as independent factors associated with increased PFS and OS (Table 5).

In addition, $48(33 \%)$ patients were treated with cetuximab, 11 in the 1st line setting and 37 in 2nd and further lines. KRAS mutational status was available in 42 of these patients and 13 $(31 \%)$ of them carried a mutation in their primary tumours. KRAS and $B R A F$ mutation were found to be mutually exclusive. KRAS status predicted resistance to cetuximab therapy in terms of decreased PFS $(P=0.045)$ and $\operatorname{mOS}(P=0.007)$. Also, four $(8.5 \%)$ patients were found to harbour a $B R A F^{\mathrm{V} 600 \mathrm{E}}$ mutation in the primary tumours. Similarly, patients with a $B R A F$ mutation presented lower PFS $(P=0.05)$ and $\operatorname{mOS}(P=0.004)$. When analysed together, the presence of either mutation was significantly correlated with decreased PFS $(P=0.013)$ and mOS $(P=0.003)$ in cetuximab-treated patients. $B R A F$ mutation retains its prognostic significance in PFS $(0.003)$ and mOS $(<0.001)$ in the subpopulation of patients that have not received cetuximab in the course of their disease.

\section{DISCUSSION}

The results of this study show that patients with $B R A F$-mutated tumours had a significantly lower median PFS and OS compared with patients with wt tumours. In addition, multivariate analysis revealed that the presence of the V600E BRAF mutation was established as an independent prognostic factor for reduced PFS and OS. Similar results have been previously reported regarding the prognostic of BRAF mutation in patients with mCRC (Samowitz et al, 2005; Souglakos et al, 2009). In this study, median OS was 31.5 months, which is higher than survival reported by other studies. This improved OS could be related to the fact that after initial response to systemic treatment, $24 \%$ of patients underwent metastasectomy; alternatively, we cannot

Table 3 Treatment regimens used in this retrospective study

\begin{tabular}{lcr}
\hline First-line regimens & N (out of 144) & \% \\
\hline FOLFOX+Bevacizumab & 33 & 23 \\
FOLFOX+Cetuximab & 9 & 6 \\
FOLFOXIRI & 67 & 46 \\
FOLFIRI & 27 & 19 \\
FOLFOX & 8 & 6 \\
Oxaliplatin-based treatment (first line) & 117 & 82 \\
Irinotecan-based treatment (first line) & 94 & 65 \\
Bevacizumab+chemotherapy (first line) & 33 & 23 \\
Oxaliplatin-based treatment (any line) & 128 & 89 \\
Irinotecan-based treatment (any line) & 123 & 85 \\
Bevacizumab+chemotherapy (any line) & 74 & 51 \\
Cetuximab+chemotherapy (any line) & 69 & 48 \\
Patients treated with all 3 chemotherapy drugs & 126 & 87 \\
Patients treated with all 5 active agents & 65 & 45 \\
\hline
\end{tabular}

Abbreviations: FOLFOX = folinic acid, 5FU, oxaliplatin; FOLFIRI = folinic acid, 5FU, irinotecan; FOLFOXIRI = folinic acid, 5FU, oxaliplatin, irinotecan. exclude that this observation may be due the fact that $87 \%$ of the patients had received all three chemotherapeutic drugs in the course of their treatment (Grothey et al, 2004; Hurwitz et al, 2004) whereas $45 \%$ of patients had also received both moAbs as well.

In this study, the incidence of $B R A F$ mutations was significantly higher in patients with MSI-H (45\%) than with MSS tumours $(1.6 \% ; P=<0.001)$, in agreement with the published evidence (Rajagopalan et al, 2002; Oliveira et al, 2003; Wang et al, 2003). Moreover, our patients with MSI-H and BRAF-mutated tumours
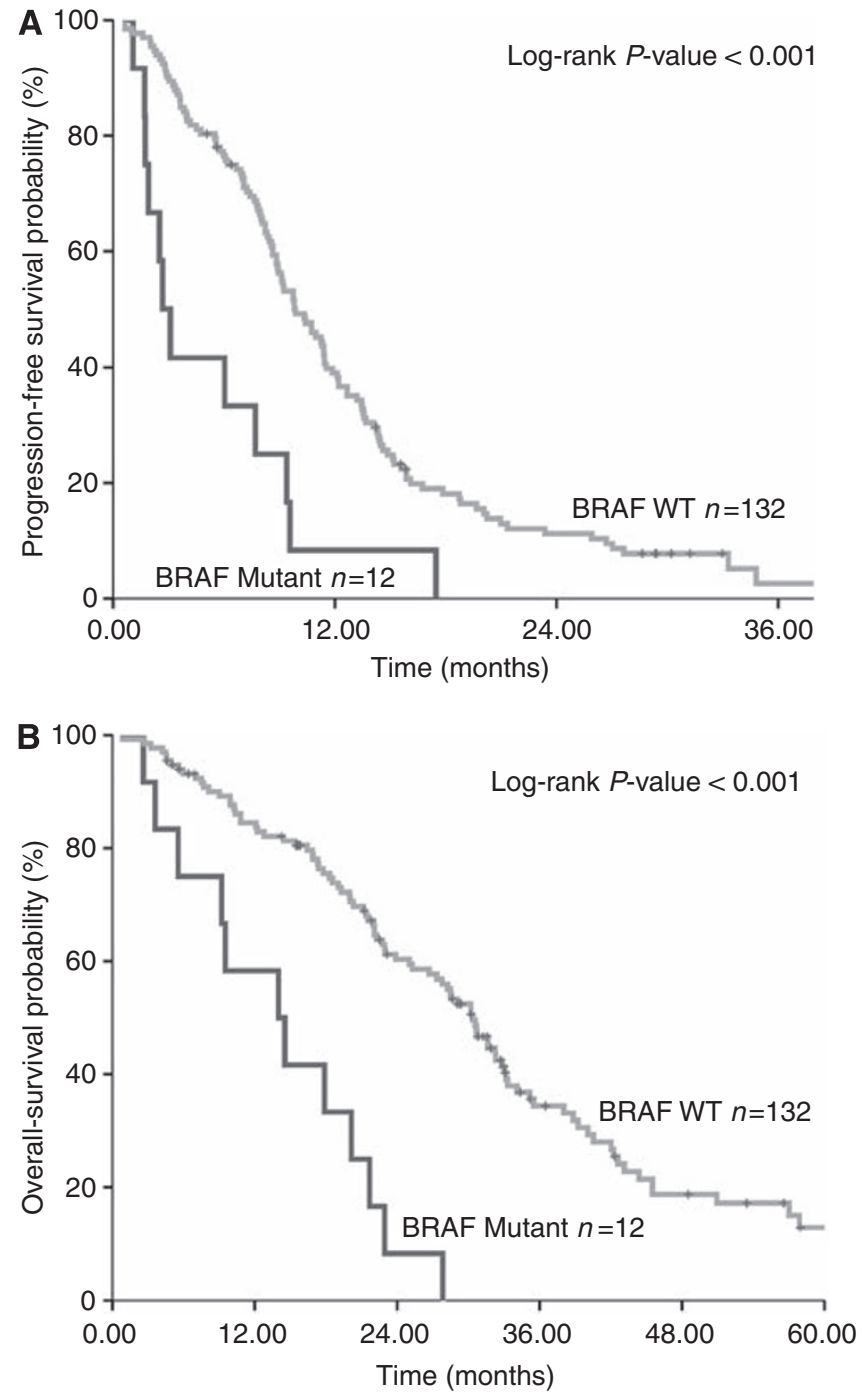

Figure 2 (A) Progression-free survival in first-line chemotherapy analysed by BRAF mutation status. (B) Overall survival, analysed by BRAF mutation status.

Table 4 Correlations of BRAF mutations with MSI status and cyclin DI expression in I 44 patients

\begin{tabular}{|c|c|c|c|c|c|c|c|c|}
\hline & \multicolumn{4}{|c|}{ MSI status, N (\%) } & \multirow[b]{2}{*}{$\begin{array}{l}\text { Overexpressed } \\
26(18)\end{array}$} & \multicolumn{3}{|c|}{ Cyclin DI, N (\%) } \\
\hline & No of patients & $\begin{array}{l}\text { High } \\
22(15)\end{array}$ & $\begin{array}{c}\text { Stable } \\
\text { I } 22(85)\end{array}$ & $P$-value ${ }^{\text {a }}$ & & $\begin{array}{c}\text { Weak expression } \\
63(44)\end{array}$ & $\begin{array}{l}\text { No expression } \\
55(38)\end{array}$ & $P$-value ${ }^{a}$ \\
\hline \multicolumn{9}{|c|}{ BRAF V600E mutation } \\
\hline $\begin{array}{l}\text { Mutant } \\
\text { Wild type }\end{array}$ & $\begin{array}{r}12 \\
132\end{array}$ & $\begin{array}{l}10(83) \\
12(9)\end{array}$ & $\begin{array}{c}2(17) \\
120(91)\end{array}$ & $<0.001$ & $\begin{array}{l}7(58) \\
19(14)\end{array}$ & $\begin{array}{l}3(25) \\
60(46)\end{array}$ & $\begin{array}{c}2(17) \\
53(40)\end{array}$ & $0.001^{b}$ \\
\hline
\end{tabular}

Abbreviation: $\mathrm{MSI}=$ microsatellite instability. ${ }^{\mathrm{a}}$ Fisher's exact test. ${ }^{\mathrm{b}}$ Overexpression vs weak or no expression. 
Table 5 Results of multivariate analysis for PFW and OS of I 44 patients

\begin{tabular}{lccc}
\hline & Hazard ratio & $\mathbf{9 5 \%} \mathbf{~ C l}$ & P-value \\
\hline Progression-free survival & & & \\
BRAF (mutant v wt) & 2.8 & $(1.4-5.7)$ & 0.004 \\
Tumor grade (3 vs I-2) & 2.0 & $(1.3-3.2)$ & 0.001 \\
Metastasectomy (yes vs no) & 0.5 & $(0.3-0.8)$ & 0.004 \\
& & & \\
Overall survival & 5.3 & $(2.5-11.3)$ & $<0.001$ \\
BRAF (mutant vs wt) & 2.6 & $(1.6-4.4)$ & $<0.001$ \\
Tumor grade (3 vs I-2) & 0.6 & $(0.3-0.9)$ & 0.02 \\
Metastasectomy (yes vs no) & 0.4 & $(0.2-0.7)$ & 0.009 \\
Number of treatment lines & & & \\
(first vs $\geqslant$ second line) & & &
\end{tabular}

Abbreviation: $\mathrm{Cl}=$ Confidence interval.

experienced significantly lower PFS $(P=0.008)$ and OS $(P=0.004)$ in comparison with those with MSI-H and BRAF wt primary tumours. Similar results have been reported regarding the prognostic significance of $B R A F$ mutations in patients with early stage CRC (Samowitz et al, 2005; French et al, 2008). In the French et al (2008) trial among patients with dMMR, BRAF wt cases had a significantly improved OS compared with those that were $B R A F$ mutated $(P=0.001)$. Samowitz et al $(2005)$ showed that patients with dMMR tumours were associated with an excellent 5-year OS regardless of the BRAF V600E status. However, they have also reported that the $B R A F$ mutation was associated with poor survival among the patients with MSS tumours (Samowitz et al, 2005). Nevertheless, the direct comparison of these studies is difficult because of differences in the studied population, and additional studies with larger groups of patients are required.

In this study, the detection of BRAF mutations was associated with cyclin D1 expression. Indeed, the incidence of cyclin D1 overexpression was significantly higher in $B R A F$-mutated $(58 \%)$ than $B R A F$ wt tumours $(14 \% ; P=0.001)$, and patients with $B R A F$ mutations and cyclin D1 overexpression had significantly decreased PFS $(P=0.03)$ and OS $(P=0.01)$ compared with patients with $B R A F$ wt tumours. The biological significance of the $B R A F$ V600E mutation and oncogenic activation in MSI-H CRC is not well established. The effect of BRAF knockdown in cellular survival and proliferation is not fully understood. It has been shown that in MSI CRC cell lines, $B R A F$ is the main activator of ERKs and these cells are more dependant on the BRAF-ERK pathway (Preto et al,

\section{REFERENCES}

Aaltonen LA, Peltomaki P, Leach FS, Sistonen P, Pylkkanen L, Mecklin JP, Jarvinen H, Powell SM, Jen J, Hamilton SR (1993) Clues to the pathogenesis of familial colorectal cancer. Science 260: 812-816

Aaltonen LA, Peltomaki P, Mecklin JP, Jarvinen H, Jass JR, Green JS, Lynch HT, Watson P, Tallqvist G, Juhola M (1994) Replication errors in benign and malignant tumors from hereditary nonpolyposis colorectal cancer patients. Cancer Res 54: $1645-1648$

Benlloch S, Paya A, Alenda C, Bessa X, Andreu M, Jover R, Castells A, Llor X, Aranda FI, Massuti B (2006) Detection of BRAF V600E mutation in colorectal cancer: comparison of automatic sequencing and real-time chemistry methodology. J Mol Diagn 8: 540-543

Bhatt KV, Hu R, Spofford LS, Aplin AE (2007) Mutant B-RAF signaling and cyclin D1 regulate Cks1/S-phase kinase-associated protein 2-mediated degradation of p27Kip1 in human melanoma cells. Oncogene 26: 1056- 1066

Bhatt KV, Spofford LS, Aram G, McMullen M, Pumiglia K, Aplin AE (2005) Adhesion control of cyclin D1 and p27Kip1 levels is deregulated in melanoma cells through BRAF-MEK-ERK signaling. Oncogene 24: $3459-3471$

Bokemeyer C, Bondarenko I, Makhson A, Hartmann JT, Aparicio J, de BF, Donea S, Ludwig H, Schuch G, Stroh C, Loos AH, Zubel A, Koralewski P (2008) Fluorouracil, leucovorin, and oxaliplatin with and without
2008). Similar to the melanoma model (Bhatt et al, 2005, 2007), in MSI CRC cells, it was shown that BRAF V600E-ERK signalling is important in the regulation of proliferation through the $\mathrm{p} 27^{\mathrm{Kip} 1}$ and cyclin D1 proteins (Preto et al, 2008).

Furthermore, the presence of BRAF mutations has been correlated with resistance to the anti-EGFR moAb cetuximab (Di Nicolantonio et al, 2008; Souglakos et al, 2009). Moreover, the introduction/presence of the BRAF V600E allele in CRC (DiFi-BRAF, COLO-205 and HT-29) cell lines impaired the therapeutic potential of anti-EGFR moAbs. In contrast, when these cells lines were treated with a combination of cetuximab and the small-molecule kinase BRAF inhibitor, sorafenib, a significant reduction in proliferation and a prominent proapoptotic effect was found, whereas, either of these agents alone had limited effects (Di Nicolantonio et al, 2008). Thus, in the clinical setting, the therapeutic effect of anti-EGFR moAbs could be restored by a two-hit approach that blocks the EGFR pathway in multiple locations. In accordance with previous reports (Di Nicolantonio et al, 2008; Souglakos et al, 2009), we found that BRAF mutation predicted resistance to cetuximab treatment in the subpopulation of patients that have received this kind of therapy. Furthermore, the prognostic impact of $B R A F$ mutation remains significant not only in the whole of the study but also in the subpopulation of patients that have not received an anti-EGFR moAbs.

In summary, BRAF V600E mutations, which are correlated with MSI-H status and cyclin D1 overexpression, characterise a subgroup of patients with poor prognosis. The findings reported in this study confirm our previous observations (Souglakos et al, 2009) as well as from other groups (Samowitz et al, 2005). Nevertheless, they need to be formally confirmed in prospective randomised clinical trials, as this subgroup of patients might justify foregoing approved treatments in favour of investigational ones. Furthermore, the adverse significance of $B R A F$ mutations could be used to stratify patients in future clinical trials because these patients carry a significant higher risk of progression and death due to the disease.

\section{ACKNOWLEDGEMENTS}

This work partly supported by research grants from the Cretan Association for Biomedical Research (CABR) and the Hellenic Oncology Research Group (HORG). Dr ZS, Dr DP-P, Dr EB and Dr HA are recipients of a CABR research fellowship. cetuximab in the first-line treatment of metastatic colorectal cancer. J Clin Oncol 27(5): 663-671

Boland CR, Thibodeau SN, Hamilton SR, Sidransky D, Eshleman JR, Burt RW, Meltzer SJ, Rodriguez-Bigas MA, Fodde R, Ranzani GN, Srivastava S (1998) A National Cancer Institute Workshop on microsatellite instability for cancer detection and familial predisposition: development of international criteria for the determination of microsatellite instability in colorectal cancer. Cancer Res 58: 5248-5257

Cunningham JM, Christensen ER, Tester DJ, Kim CY, Roche PC, Burgart LJ, Thibodeau SN (1998) Hypermethylation of the hMLH1 promoter in colon cancer with microsatellite instability. Cancer Res 58: 3455-3460

Cunningham JM, Kim CY, Christensen ER, Tester DJ, Parc Y, Burgart LJ, Halling KC, McDonnell SK, Schaid DJ, Walsh VC, Kubly V, Nelson H, Michels VV, Thibodeau SN (2001) The frequency of hereditary defective mismatch repair in a prospective series of unselected colorectal carcinomas. Am J Hum Genet 69: 780-790

Davies H, Bignell GR, Cox C, Stephens P, Edkins S, Clegg S, Teague J, Woffendin H, Garnett MJ, Bottomley W, Davis N, Dicks E, Ewing R, Floyd Y, Gray K, Hall S, Hawes R, Hughes J, Kosmidou V, Menzies A, Mould C, Parker A, Stevens C, Watt S, Hooper S, Wilson R, Jayatilake H, Gusterson BA, Cooper C, Shipley J, Hargrave D, Pritchard-Jones K, 
Maitland N, Chenevix-Trench G, Riggins GJ, Bigner DD, Palmieri G, Cossu A, Flanagan A, Nicholson A, Ho JW, Leung SY, Yuen ST, Weber BL, Seigler HF, Darrow TL, Paterson H, Marais R, Marshall CJ, Wooster R, Stratton MR, Futreal PA (2002) Mutations of the BRAF gene in human cancer. Nature 417: 949-954

Di Nicolantonio F, Martini M, Molinari F, Sartore-Bianchi A, Arena S, Saletti P, De DS, Mazzucchelli L, Frattini M, Siena S, Bardelli A (2008) Wild-type BRAF is required for response to panitumumab or cetuximab in metastatic colorectal cancer. J Clin Oncol 26: 5705-5712

Domingo E, Laiho P, Ollikainen M, Pinto M, Wang L, French AJ, Westra J, Frebourg T, Espin E, Armengol M, Hamelin R, Yamamoto H, Hofstra RM, Seruca R, Lindblom A, Peltomaki P, Thibodeau SN, Aaltonen LA, Schwartz Jr S (2004) BRAF screening as a low-cost effective strategy for simplifying HNPCC genetic testing. J Med Genet 41: 664-668

Douillard J, Siena S, Cassidy J, Tabernero J, Burkes R, Barugel ME, Humblet Y, Cunningham D, Wolf M, Gansert JL (2009) Randomized phase 3 study of panitumumab with FOLFOX4 compared to FOLFOX4 alone as 1st-line treatment (tx) for metastatic colorectal cancer (mCRC): the PRIME trial. Ann Oncol (Suppl) 7(3): 6. Ref type: abstract

Emmanouilides C, Sfakiotaki G, Androulakis N, Kalbakis K, Christophylakis C, Kalykaki A, Vamvakas L, Kotsakis A, Agelaki S, Diamandidou E, Touroutoglou N, Chatzidakis A, Georgoulias V, Mavroudis D, Souglakos J (2007) Front-line bevacizumab in combination with oxaliplatin, leucovorin and 5-fluorouracil (FOLFOX) in patients with metastatic colorectal cancer: a multicenter phase II study. BMC Cancer 7: 91

French AJ, Sargent DJ, Burgart LJ, Foster NR, Kabat BF, Goldberg R, Shepherd L, Windschitl HE, Thibodeau SN (2008) Prognostic significance of defective mismatch repair and BRAF V600E in patients with colon cancer. Clin Cancer Res 14: 3408-3415

Grothey A, Sargent D, Goldberg RM, Schmoll HJ (2004) Survival of patients with advanced colorectal cancer improves with the availability of fluorouracil-leucovorin, irinotecan, and oxaliplatin in the course of treatment. J Clin Oncol 22: 1209-1214

Gryfe R, Kim H, Hsieh ET, Aronson MD, Holowaty EJ, Bull SB, Redston M, Gallinger S (2000) Tumor microsatellite instability and clinical outcome in young patients with colorectal cancer. $N$ Engl J Med 342: 69-77

Hecht JR, Mitchell E, Chidiac T, Scroggin C, Hagenstad C, Spigel D, Marshall J, Cohn A, McCollum D, Stella P, Deeter R, Shahin S, Amado RG (2009) A randomized phase IIIB trial of chemotherapy, bevacizumab, and panitumumab compared with chemotherapy and bevacizumab alone for metastatic colorectal cancer. J Clin Oncol 27: 672-680

Hemminki A, Mecklin JP, Jarvinen H, Aaltonen LA, Joensuu H (2000) Microsatellite instability is a favorable prognostic indicator in patients with colorectal cancer receiving chemotherapy. Gastroenterology 119: 921-928

Hurwitz H, Fehrenbacher L, Novotny W, Cartwright T, Hainsworth J, Heim W, Berlin J, Baron A, Griffing S, Holmgren E, Ferrara N, Fyfe G, Rogers B, Ross R, Kabbinavar F (2004) Bevacizumab plus irinotecan, fluorouracil, and leucovorin for metastatic colorectal cancer. $N$ Engl J Med 350: $2335-2342$

Jemal A, Siegel R, Ward E, Hao Y, Xu J, Thun MJ (2009) Cancer statistics, 2009. CA Cancer J Clin 59: 225-249

Kane MF, Loda M, Gaida GM, Lipman J, Mishra R, Goldman H, Jessup JM, Kolodner R (1997) Methylation of the hMLH1 promoter correlates with lack of expression of hMLH1 in sporadic colon tumors and mismatch repair-defective human tumor cell lines. Cancer Res 57: 808-811

Kobayashi S, Shimamura T, Monti S, Steidl U, Hetherington CJ, Lowell AM, Golub T, Meyerson M, Tenen DG, Shapiro GI, Halmos B (2006) Transcriptional profiling identifies cyclin D1 as a critical downstream effector of mutant epidermal growth factor receptor signaling. Cancer Res 66: $11389-11398$

Le Marchand L, Seifried A, Lum-Jones A, Donlon T, Wilkens LR (2003) Association of the cyclin D1 A870G polymorphism with advanced colorectal cancer. JAMA 290: 2843 - 2848

Leach FS, Nicolaides NC, Papadopoulos N, Liu B, Jen J, Parsons R, Peltomaki P, Sistonen P, Aaltonen LA, Nystrom-Lahti M (1993) Mutations of a mutS homolog in hereditary nonpolyposis colorectal cancer. Cell 75: 1215-1225

Lindor NM, Burgart LJ, Leontovich O, Goldberg RM, Cunningham JM, Sargent DJ, Walsh-Vockley C, Petersen GM, Walsh MD, Leggett BA, Young JP, Barker MA, Jass JR, Hopper J, Gallinger S, Bapat B, Redston M, Thibodeau SN (2002) Immunohistochemistry versus microsatellite instability testing in phenotyping colorectal tumors. J Clin Oncol 20: 1043-1048
Makino R, Yazyu H, Kishimoto Y, Sekiya T, Hayashi K (1992) F-SSCP: fluorescence-based polymerase chain reaction-single-strand conformation polymorphism (PCR-SSCP) analysis. PCR Methods Appl 2: $10-13$

Nosho K, Kawasaki T, Chan AT, Ohnishi M, Suemoto Y, Kirkner GJ, Fuchs CS, Ogino S (2008) Cyclin D1 is frequently overexpressed in microsatellite unstable colorectal cancer, independent of $\mathrm{CPG}$ island methylator phenotype. Histopathology 53: 588-598

Oliveira C, Pinto M, Duval A, Brennetot C, Domingo E, Espin E, Armengol M, Yamamoto H, Hamelin R, Seruca R, Schwartz Jr S (2003) BRAF mutations characterize colon but not gastric cancer with mismatch repair deficiency. Oncogene 22: $9192-9196$

Peltomaki PT (1994) Genetic basis of hereditary nonpolyposis colorectal carcinoma (HNPCC). Ann Med 26: 215-219

Peyssonnaux C, Eychene A (2001) The Raf/MEK/ERK pathway: new concepts of activation. Biol Cell 93: 53-62

Popat S, Hubner R, Houlston RS (2005) Systematic review of microsatellite instability and colorectal cancer prognosis. J Clin Oncol 23: 609-618

Preto A, Figueiredo J, Velho S, Ribeiro AS, Soares P, Oliveira C, Seruca R (2008) BRAF provides proliferation and survival signals in MSI colorectal carcinoma cells displaying BRAF(V600E) but not KRAS mutations. J Pathol 214: 320-327

Rajagopalan H, Bardelli A, Lengauer C, Kinzler KW, Vogelstein B, Velculescu VE (2002) Tumorigenesis: RAF/RAS oncogenes and mismatch-repair status. Nature 418: 934

Samowitz WS, Curtin K, Ma KN, Schaffer D, Coleman LW, Leppert M, Slattery ML (2001) Microsatellite instability in sporadic colon cancer is associated with an improved prognosis at the population level. Cancer Epidemiol Biomarkers Prev 10: 917-923

Samowitz WS, Sweeney C, Herrick J, Albertsen H, Levin TR, Murtaugh MA, Wolff RK, Slattery ML (2005) Poor survival associated with the BRAF V600E mutation in microsatellite-stable colon cancers. Cancer Res 65 $6063-6069$

Saridaki Z, Liloglou T, Zafiropoulos A, Koumantaki E, Zoras O, Spandidos DA (2003) Mutational analysis of $C D K N 2 A$ genes in patients with squamous cell carcinoma of the skin. Br J Dermatol 148: 638-648

Souglakos J, Androulakis N, Syrigos K, Polyzos A, Ziras N, Athanasiadis A, Kakolyris S, Tsousis S, Kouroussis C, Vamvakas L, Kalykaki A, Samonis G, Mavroudis D, Georgoulias V (2006) FOLFOXIRI (folinic acid, 5-fluorouracil, oxaliplatin and irinotecan) vs FOLFIRI (folinic acid, 5-fluorouracil and irinotecan) as first-line treatment in metastatic colorectal cancer (MCC): a multicentre randomised phase III trial from the Hellenic Oncology Research Group (HORG). Br J Cancer 94: 798-805

Souglakos J, Philips J, Wang R, Marwah S, Silver M, Tzardi M, Silver J, Ogino S, Hooshmand S, Kwak E, Freed E, Meyerhardt JA, Saridaki Z, Georgoulias V, Finkelstein D, Fuchs CS, Kulke MH, Shivdasani RA (2009) Prognostic and predictive value of common mutations for treatment response and survival in patients with metastatic colorectal cancer. $\mathrm{Br} \mathrm{J}$ Cancer 101: $465-472$

Thibodeau SN, Bren G, Schaid D (1993) Microsatellite instability in cancer of the proximal colon. Science 260: 816-819

Thibodeau SN, French AJ, Cunningham JM, Tester D, Burgart LJ, Roche PC, McDonnell SK, Schaid DJ, Vockley CW, Michels VV Farr Jr GH, O'Connell MJ (1998) Microsatellite instability in colorectal cancer: different mutator phenotypes and the principal involvement of hMLH1. Cancer Res 58: 1713-1718

Tol J, Koopman M, Cats A, Rodenburg CJ, Creemers GJ, Schrama JG, Erdkamp FL, Vos AH, van Groeningen CJ, Sinnige HA, Richel DJ, Voest EE, Dijkstra JR, Vink-Borger ME, Antonini NF, Mol L, van Krieken JH, Dalesio O, Punt CJ (2009) Chemotherapy, bevacizumab, and cetuximab in metastatic colorectal cancer. $N$ Engl J Med 360: $563-572$

Van Cutsem E, Kohne CH, Hitre E, Zaluski J, Chang Chien CR, Makhson A, $\mathrm{D}^{\prime}$ Haens G, Pinter T, Lim R, Bodoky G, Roh JK, Folprecht G, Ruff P Stroh C, Tejpar S, Schlichting M, Nippgen J, Rougier P (2009) Cetuximab and chemotherapy as initial treatment for metastatic colorectal cancer. $N$ Engl J Med 360: 1408-1417

Wang L, Cunningham JM, Winters JL, Guenther JC, French AJ, Boardman LA, Burgart LJ, McDonnell SK, Schaid DJ, Thibodeau SN (2003) BRAF mutations in colon cancer are not likely attributable to defective DNA mismatch repair. Cancer Res 63: 5209-5212

Watanabe T, Wu TT, Catalano PJ, Ueki T, Satriano R, Haller DG, Benson III AB, Hamilton SR (2001) Molecular predictors of survival after adjuvant chemotherapy for colon cancer. $N$ Engl J Med 344: 1196-1206 